\title{
Gonad ultrasonography image preprocessing for Mahseer (Tor Tombroides)
}

\begin{abstract}
In the context of breeding and seed production of Mahseer species, understanding and control of the Mahseer gonad maturation level have given strong interest for scientific and commercial purposes. Possible use of ultrasonography for monitoring of gonad maturation in Mahseer fish is investigated. From previous studies, ultrasonography image of gonad can be affected by many speckle noise. Subtle differences between speckle noise and the Mahseer eggs lead to difficulties in identifying the eggs in ultrasonography gonad's image. To eliminate these speckle noise, preprocessing image method is required. Filtering despeckling techniques is initially applied to remove the noise. There will be experimenting in comparing which despeckling technique is suitable for the gonad's ultrasonography image. From the result, the best despeckling technique will be chosen and a framework of preprocessing method will be introduced for identifying the eggs in the gonad ultrasonography image. This noninvasive tool can then obviously be utilized to improve and monitor the maturation level of Mahseer fish. Ultrasonography thus has great potential for use in Mahseer fish both for conservation and aquaculture field. To our knowledge, this is the first article on the preprocessing of ultrasonography image on Mahseer or any fish species.
\end{abstract}

Keyword: Image preprocessing; Filtering; Morphological operation; Mahseer; Ultrasonography 